\title{
Patent Pools for ARVs: Industry Perspectives from ASPEN
}

\author{
Stavros Nicolaou*
}

Pharmacare Limited t/a Aspen, Building 7, Healthcare Park, Woodlands Drive, Woodmead, Sandton, P.O. Box 1593, Gallo Manor, 2052, South Africa

\begin{abstract}
Affordability through reduced pricing is only one part of enhancing access to treatment in Public Health emergencies: Supply Security and the guarantee of supply consistency is the other.

To the extent that Patent Pooling is able to create Regional African Manufacturing capability, Africans will support the concept. However, to the extent that if further decentralises manufacture away from the continent and increases Africa's dependence on imports, Patent Pooling can potentially weaken supply security and will continue to relegate Africa a Continent of dependency, rather than one that invests in its own capability.

Patent Pooling, should be viewed guardedly on the African Continent and will only be embraced, provided it is consistent with the AU Heads of State call for an African Manufacturing Plan and Africa's aspiration to more from "converting charity dollars into sustainable, long term investment dollars".
\end{abstract}

\section{AFRICA SHOULD MANUFACTURE ITS OWN DRUGS}

Tremendous progress has been made in recent times in enhancing and accelerating access to treatment with first line ARVs to patients in Sub - Saharan Africa [1,2]. This has largely occurred, as a consequence of the introduction of generic products, bought about by the collaboration between the $R \& D$ based industry and generic producers and the ability to drive down raw material prices $[3,4]$.

To this end, it should be noted that affordability through reduced pricing is one aspect of enhancing access to treatment, however it is not the only one.

A very important aspect to the access of treatment debate, is that of supply security. The reduction of price, as welcome as it might be, becomes largely meaningless, unless supply security and the guarantee in consistency of supply is ensured. It is for this reason and others, that the African Union heads of state summit in Abudja in 2004 called for an African Pharmaceutical manufacturing plan, where the establishment of regional pharmaceutical manufacturing capability became an alternative to the dependency created by Pharmaceutical imports. It seemed that Africa, a significant net importer of Pharmaceutical products, particularly in those high volume therapeutic areas that are endemic to the Sub Saharan region was missing a significant opportunity in developing its own Pharmaceutical capacity and capability and hence lessening its dependence on imports.

\footnotetext{
*Address correspondence to this author at the Pharmacare Limited t/a Aspen, Building 7, Healthcare Park, Woodlands Drive, Woodmead, Sandton, P.O. Box 1593, Gallo Manor, 2052, South Africa; Tel: +2711 239 3500/+2711239 6734; Fax: +2711239 6018;

E-mail: nicolaous@aspenpharma.com
}

\section{ENTWINING IMPORTS WITH LOCALLY PRODUCED DRUGS}

The Current trend of importing even the most basic and high volume pharmaceuticals continues to exacerbate the old adage that Africa is incapable of manufacturing and or developing high tech products. This mind set lends itself to the continued outflow of skills, technology, capital and economic value from the continent to foreign destinations. It also places supply security at risk and denies the continent developmental opportunities. A model which provides the appropriate mix between locally produced products and imports is a far more viable and sustainable option in the long term.

Consequently, whilst patent pools can offer much in terms of accelerating access to treatment, particularly in those epidemiologies that remain pervasive in Africa, due recognition and cognizance of local manufacturing and its benefits to both the people and Economies of the Sub Saharan region cannot be understated [5]. It stands to reason, that Africa needs to develop and entrench its own capabilities in those areas that are socio economically critical to the continent. Infectious diseases that are endemic on the continent, most certainly fall in the category of some of the keenest and most important socio economic challenges that confront the continent. Africa cannot continue to stand by and watch the hitherto culture of developmental dependency, as not only does it place its future in the hands of others, but this perpetuates the culture of expecting indefinite hand outs from Donor funders, rather than taking its future and destiny into its own hands.

\section{THE APPROPRIATE BALANCE}

The frequently mentioned dictum "Teach a man to fish, rather than donating a daily fish and keeping the man 
without a fishing rod" needs to begin to be applied in the context of Pharmaceutical interventions in African Public Health emergencies. Voluntary pooling of patents provides an ideal opportunity for this to begin occurring and for serious attempts at the development of regional manufacturing capability to be taken to heart. To the extent that patent pooling can contribute to this and the prospects of confronting Africa's socio economic challenges through the creation of economic value added beneficiation to the benefit of Africa and its people, we need to support it.

\section{REFERENCES}

[1] Souteyrand Y. Global and regional progress in 2008. WHO presentation. Available at: http://www.who.int/hiv/mediacentre/ statem ent_july2009/en/print.html (accessed July 2009)
[2] Sixty-first World Health Assembly 24 May 2008: Global strategy and plan of action on public health, innovation and intellectual property. Available from: http://www.who.int/gb/ebwha/pdf_files/ A61/A61 R21-en.pdf

[3] Dionisio D, Khanna AK, Nicolaou S, et al. For-profit policies and equitable access to antiretroviral drugs in resource-limited countries. Future HIV Therapy 2008; 2(1): 25-36. Available at: http://www.futuremedicine.com/toc/fht $/ 2 / 1$

[4] Dionisio D, Gass R, McDermott P, et al. What strategies to boost production of affordable fixed-dose antiretroviral drug combinations for children in the developing world? Curr HIV Res 2007; 5: 155-87. Available at: http://www.ingentaconnect. com/co ntent/ben/chr/2007/00000005/00000002/art00002 (accessed July 2009)

[5] Bermudez J. Access to medicines and IPR: UNITAID moving towards a patent pool? UNITAID second consultative forum (Dakar, Senegal, 6 December 2008). Available from : http://www. unitaid.eu/index.php/en/NEWS/UNITAID-Consultative-Forum-20 08.html 